(c) American Dairy Science Association, 2003.

\title{
Estimation of Genetic Parameters for Concentrations of Milk Urea Nitrogen
}

\author{
G. M. Wood, ${ }^{\star}$ P. J. Boettcher, ${ }^{\star \ddagger}$ J. Jamrozik, ${ }^{\star}$ G. B. Jansen, ${ }^{\star}$ and D. F. Kelton† \\ *Department of Animal and Poultry Science and \\ †Department of Population Medicine \\ University of Guelph, Ontario N1G 2W1 Canada \\ fInstitute of Agricultural Biology and Biotechnology, National Research Council \\ Segrate 20090 Italy
}

\section{ABSTRACT}

The objective of this study was to use field data collected by dairy herd improvement programs to estimate genetic parameters for concentrations of milk urea nitrogen (MUN). Edited data were 36,074 test-day records of MUN and yields of milk, fat, and protein obtained from 6102 cows in Holstein herds in Ontario, Canada. Data were divided into three sets, for the first three lactations. Two analyses were performed on data from each lactation. The first procedure used ANOVA to estimate the significance of the effects of several environmental factors on MUN. Herd-test-day effects had the most significant impact on MUN. Effects of stage of lactation were also important, and MUN levels tended to increase from the time of peak yield until the end of lactation. The second analysis used a random regression model to estimate heritabilities and genetic correlations of MUN and the yield traits. Heritability estimates for MUN in lactations one, two, and three were $0.44,0.59$, and 0.48 , respectively. Heritabilities for the yield traits were of a similar magnitude. Little relationship was observed between MUN and yield. Raw phenotypic correlations were all $<0.10$ (absolute value). Genetic correlations with production traits were close to zero in lactations one and three and only slightly positive in lactation two. The results indicate that selection on MUN is possible, but relationships between MUN and other economically important traits such as metabolic disease and fertility are needed.

(Key words: milk urea nitrogen, genetic parameter)

Abbreviation key: CTDM= Canadian test-day model, HTD = herd-test-day, IR = infrared, $\mathbf{M U N}=$ milk urea nitrogen, $\mathbf{W C}=$ wet chemistry.

Received January 29, 2003.

Accepted February 24, 2003.

Corresponding author: P. Boettcher; e-mail: boettch@ibba.cnr.it.

\section{INTRODUCTION}

The high producing dairy cow is under high metabolic demand during the period immediately following parturition due to the metabolic demands of increased milk production largely achieved through breeding programs that have emphasized increased yield. The ability to handle these stresses without becoming ill is extremely important, from both an animal welfare and economic perspective.

Development of tests to enable producers to diagnose metabolic problems to meet the needs of the transition or early-lactation cow in a cost-effective manner is the current focus of research into measures of protein and energy status. The collection across farms, organization, and analysis of data regarding these tests may, in turn, provide information about genetic factors associated with metabolic stress and may be used in selection decisions.

Levels of urea nitrogen in the milk, also known as milk urea nitrogen (MUN), is an example of a test that, along with other characteristics, may help indicate the level of metabolic stress a cow is encountering, particularly early in lactation (Eicher et al., 1999). The breakdown of dietary protein for energy results in the production of ammonia. Ammonia is highly toxic and must be converted to urea by the kidneys and liver. Urea is a nontoxic molecule of carbon, nitrogen, oxygen, and hydrogen. It may be present at very high levels without causing adverse effects to the health of the cow. Urea diffuses easily and is excreted from the body in the urine and milk. Urea is considered a normal component of milk and is part of the NPN found in milk (Ferguson, 2002). Levels of MUN are currently used as an indication of whether cows are consuming the proper quantities and proportions of protein and energy in their diets (Jonker et al., 1998). The concentration of MUN is known to vary with the amount of protein in the diet, amount of urine excreted, amount of water intake, and the amount of DMI (Ferguson, 2002). Concentrations of MUN may also differ even in cows consuming the same diet, due to genetic differences in the ability to 
metabolize protein, although to date no published studies have investigated this possibility.

The measurement and recording of MUN is important in estimating the protein nutrition of cows and aids in the identification of energy balance problems (Eicher et al., 1999). The potential exists for this information to be useful to producers from the genetic perspective and for management. To evaluate this potential, the magnitude of genetic and environmental factors that influence MUN must be determined.

The objectives of this study were: 1 ) to determine the effects of systematic environmental influences on MUN, and 2) to estimate genetic variances for MUN, including genetic correlations of MUN with yields of milk, fat, and yield. A test-day model was applied to data for the various traits and genetic effects were estimated using random-regressions.

\section{MATERIALS AND METHODS}

\section{Data}

Phenotypic data. The data for this study were collected by the Ontario Dairy Herd Improvement corporation (Guelph, Ontario, Canada) between July 1997 and December 1999. Milk samples collected on regular test days from registered Holstein cattle in 202 Southern Ontario dairy herds were tested for MUN as an option of the standard program that evaluates concentrations of fat, protein, and somatic cells in milk. The test for MUN uses infrared (IR) technology and is an option that has been offered to producers by Ontario DHI for several years. In total, 288,785 test-day records were provided, of which 86,016 contained a valid MUN score.

The data were first edited to eliminate records with daily milk, fat, or protein yields $>99,9$, and $6 \mathrm{~kg}$, respectively. Records without information for yields were also deleted. A standard 305-d lactation length was imposed by removing all records with $<5$ or $>305$ DIM. Records were also eliminated if no registration number was present for a given cow, because for these animals no pedigree information would be available for the genetic analysis. Analyses of the MUN data were applied to only the first three parities and, therefore, data from later parities were also discarded. Ages at calving were required to be between 18 and 40, 28 and 49 , and 40 and 68 mo in lactations one, two, and three, respectively. Following these edits, only those records from cows with at least four test-day records in a given lactation were retained for analysis, leaving an initial total of 45,134 records from 6704 cows.

Pedigree data. The pedigree information used in this study was extracted from the database used for the national genetic evaluation of dairy traits in Canada, which had been provided by the Canadian Dairy Net- work (Guelph, Ontario). The 6704 unique cow registration numbers from the file of phenotypic records were matched to the national pedigree file, and only cows with a known sire were retained. Cows with discrepancies for sire or birth date between the two files were also removed, leaving 6102 cows (795 sires) in the dataset. Four generations of pedigree information was extracted from the national pedigree file. The addition of dams without records, sires, and four generations of ancestors resulted in a pedigree containing 14,375 animals.

The fully edited and coded pedigree was then matched back to the data file. The final data set used for the subsequent analyses contained 36,074 test-day records. Observations from different lactations were considered to be distinct traits. The data included 16,030; 12,196; and 7848 records from lactations one, two, and three, respectively.

\section{Analyses}

Environmental effects. An ANOVA of the effects of certain systematic factors on test-day MUN was performed using the GLM procedure in SAS (SAS Institute Inc., 1990). The environmental factors that were considered for inclusion in the eventual genetic analysis were tested for significant contributions to the variation in MUN. Herd-test-days (HTD) were used to define contemporary groups. The numbers of HTD were 1496, 1509 , and 1419 in lactations one, two and three, respectively. Three classes for age-at-calving (in mo) were established for each lactation (first: 18 to 24,25 to 29, and 30 to $40 \mathrm{mo}$; second: 28 to 38,39 to 41 , and 42 to $49 \mathrm{mo}$; and third: 40 to 50,51 to 57,58 to $68 \mathrm{mo}$ ). Seasons of calving were summer (April to September) and winter (October to March). Stage of lactation was defined by 31 classes for DIM $(<10,11-20, \ldots, 290-300$, $\geq 300$ ). The following model was used to apply the test to data from each lactation separately:

$$
\begin{gathered}
\mathrm{y}_{\mathrm{ijklm}}=\mathrm{HTD}_{\mathrm{i}}+\left(\mathrm{AS}^{*} \mathrm{DIM}\right)_{\mathrm{jk}}+\mathrm{b}_{1}\left(\mathrm{MY}_{\mathrm{ijkl}}\right) \\
+\mathrm{b}_{2}\left(\mathrm{FY}_{\mathrm{ijkl}}\right)+\mathrm{b}_{3}\left(\mathrm{PY}_{\mathrm{ijkl}}\right)+\operatorname{cow}_{\mathrm{l}}+\mathrm{e}_{\mathrm{ijklm}}
\end{gathered}
$$

where $\mathrm{y}_{\mathrm{ijkl}}=$ the observed value for MUN associated

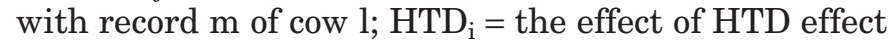
i; $\mathrm{AS}^{*} \mathrm{DIM}=$ the effect of the combination of the jth ageseason and the kth class for DIM class; $\mathrm{MY}_{\mathrm{ijk}}=$ testday milk yield for record $\mathrm{m}$ of cow $\mathrm{l} ; \mathrm{FY}_{\mathrm{ijkl}}=$ test-day fat yield for record $\mathrm{m}$ of cow $\mathrm{l}, \mathrm{PY}_{\mathrm{ijkl}}=$ test-day protein yield for record $\mathrm{m}$ of cow $\mathrm{l} ; \mathrm{b}_{\mathrm{n}}=$ coefficients for the regression of MUN on test-day yields of milk $(n=1)$, fat $(n=2)$, and protein $(n=3) ; c^{c o w}=$ the random effect of the lth cow; and $\mathrm{e}_{\mathrm{ijklm}}=$ residual error.

Genetic effects. The estimation of genetic parameters of MUN was performed using three separate four- 
trait random regression models. Random regression models (RRM) were chosen for the genetic analysis of test-day data because RRM are able to model differences in genetic effects across time and, therefore, estimate unique lactation curves for every animal (Jamrozik and Schaeffer, 1997). Linear functions of both random and fixed coefficients and a set of covariates were used to describe the shape of individual curves (Jamrozik et al., 1997). The fixed regressions described the general shape of the curve for all cows belonging to a particular subclass for a given environmental effect, while the random regressions described the deviations (due to genetic and permanent environmental effects) of each cow from the fixed regressions. The Canadian Test-day Model (CTDM; Schaeffer et al., 2000) was used as template for the analysis of these data. The CTDM analyzes four traits (milk, fat, protein, SCS) in the first three lactations (for a total of 12 traits). Because these data were collected over a relatively short period of time, the number of animals with multiple records across lactations was insufficient to make the full CTDM feasible. With respect to the CTDM, the trait SCS was replaced by MUN and each of the first three lactations was analyzed separately. In addition, because fewer data were used in this study than in the CTDM, a more complex function could be used for the regression equations. The models used for the MUN analysis contained Legendre polynomials of order 4 as described by Jamrozik et al. (2002). In contrast, the CTDM has used a regression equation that has only three parameters (Schaeffer et al. 2000).

The observation vector for any animal on a given testday can be represented by:

$$
\mathbf{y}_{\mathrm{t}: \mathrm{ijk}}=\left[\begin{array}{c}
y_{1 t}: i j k \\
y_{2 t}: i j k \\
y_{3 t}: i j k \\
y_{4}: i j k
\end{array}\right]=\left[\begin{array}{c}
24 h \text { milk yield } \\
24 h \text { fat yield } \\
24 h \text { protein yield } \\
\text { MUN score }
\end{array}\right]
$$

The model equation for all four traits in each of the three lactations was the same. The following model was used:

$$
\begin{gathered}
y_{h t: i j k}=H T D_{h: i}+\sum_{m=0}^{4} \beta_{h: j m} z_{t m}+\sum_{m=0}^{4} a_{h: k m} z_{t m} \\
+\sum_{m=0}^{4} p_{h: k m} z_{t m}+e_{h t: i j k}
\end{gathered}
$$

where $y_{h t: i j k}$ is the record of cow $k$, for trait $h$, on DIM $t$, within herd-test-day effect $i$ and belonging to ageseason subclass j; $\mathrm{HTD}_{\mathrm{h}: \mathrm{i}}$ is the herd-test date parity effect; $\beta_{\mathrm{h}: \mathrm{jm}}$ are the fixed regression coefficients which are specific to each age-season of calving subclass ( $\mathrm{j}$ ) and trait (h); $a_{h: k m}$ are the random regression coefficients for the additive genetic effects, which differ by trait (h) and are specific to each animal $(\mathrm{k}) ; \mathrm{p}_{\mathrm{h}: \mathrm{km}}$ are the random regression coefficients for the permanent environment of each animal (k) and trait (h); and finally, $\mathrm{e}_{\mathrm{ht}: \mathrm{ijk}}$ are the residual effects for each record. The covariates associated with DIM, $\mathrm{z}_{\mathrm{tm}}$, were 4th order Legendre polynomials and were the same for both the fixed and random regressions and,

$$
\begin{aligned}
& \mathrm{z}_{\mathrm{t} 0}=1.0 \\
& \mathrm{z}_{\mathrm{t} 1}=3.0^{0.5} \mathrm{x} \\
& \mathrm{z}_{\mathrm{t} 2}=5.0^{0.5}\left(1.5 \mathrm{x}^{2}-0.5\right) \\
& \mathrm{z}_{\mathrm{t} 3}=7.0^{0.5}\left(2.5 \mathrm{x}^{3}-1.5 \mathrm{x}\right) \\
& \mathrm{z}_{\mathrm{t} 4}=9.0^{0.5}\left(35 \mathrm{x}^{4}-30 \mathrm{x}^{2}+3\right) / 8
\end{aligned}
$$

where $\mathrm{x}=2(\mathrm{DIM}-5) / 300-1$ (DIM standardized in the interval from -1 to +1 ).

The age-season effects were assigned using the identical procedure as had been used for the analysis of fixed effects [equation 1]. Specifically, six age-season groups were used per parity and were defined by combinations of two seasons and three age groups.

The distribution of random effects of animal (additive genetic) and permanent environmental effects was multivariate normal and were described by covariance matrices of order 20 (4 traits $\times 5$ regression coefficients per lactation). Residual effects were assumed to be normally distributed with means of 0.0 and variances that depended upon DIM. Four periods of lactation were defined with different residual variances: 1) 5 to 45 , 2) 46 to 115,3$) 116$ to 265 , and 4) 266 to 305 DIM, respectively. These periods were chosen based on the periods currently used in the CTDM for production traits (Schaeffer et al., 2000).

A Bayesian analysis was performed and Gibbs sampling was used to obtain marginal posterior distributions for the various parameters. The HTD effects were sampled from normal distributions; regression coefficients describing the effects of age-season, animal, and permanent environment were sampled from multivariate normal distributions; covariance matrices were sampled from Wishart distributions, and residual variances were sampled from inverted chi-square distributions.

Two chains of 100,000 cycles were run for first lactation to test convergence as indicated by the similarity of estimates from the two chains. Single chains of 100,000 iterates were then run for lactations two and three. The first 10,000 iterates of each chain were regarded as a burn-in period to allow sampling from the proper marginal distributions. The length of this burn-in period was determined by visually inspecting plots of sam- 
Table 1. Means and standard deviations of test-day observations for concentrations of milk urea nitrogen (MUN) and yields of milk, fat, and protein for each lactation.

\begin{tabular}{|c|c|c|c|c|c|c|}
\hline \multirow[b]{2}{*}{ Trait } & \multicolumn{2}{|c|}{ First $(\mathrm{n}=16,030)$} & \multicolumn{2}{|c|}{ Second $(n=12,196)$} & \multicolumn{2}{|c|}{ Third $(\mathrm{n}=7848)$} \\
\hline & Mean & SD & Mean & SD & Mean & SD \\
\hline MUN, mg/dl & 12.41 & 3.31 & 12.80 & 3.50 & 12.74 & 3.45 \\
\hline Milk, kg & 29.79 & 6.28 & 33.42 & 9.25 & 35.40 & 9.97 \\
\hline Fat, kg & 1.06 & 0.24 & 1.19 & 0.36 & 1.26 & 0.40 \\
\hline Protein, kg & 0.94 & 0.18 & 1.06 & 0.25 & 1.10 & 0.27 \\
\hline
\end{tabular}

ple values across rounds. The total number of iterations $(100,000)$ was determined by previous research that applied a similar model to another set of data (our unpublished results, 2002).

The parameters of particular interest were heritabilities of the various traits and genetic correlations among the traits. Heritabilities of average yield and MUN levels over the lactation were calculated from genetic and permanent environmental variances of the first Legendre coefficient, $\left(\mathrm{Va}_{\mathrm{h}: \mathrm{k} 0}\right)$ and $\left(\mathrm{Vp}_{\mathrm{h}: \mathrm{k} 0}\right)$, and weighted average residual variance, $\left(V^{h t: i j k}\right)$, with weights proportional to the lengths of the four periods for the residual variance $(41,70,150$, and $40 \mathrm{~d}$ ), as follows:

$$
h^{2}=\frac{V\left(301^{*} a_{h: k 0}\right)}{V\left(301^{*} a_{h: k 0}\right)+V\left(301^{*} p_{h: k 0}\right)+\sum_{t=1}^{301} V\left(e_{h t: i j k}\right)} .
$$

Only the first coefficient is necessary for this calculation of variances and heritability because of properties of Legendre polynomials. The residual variance causes deviations in heritability during different periods of the lactation, so this variability in residual variance must be accounted for in the calculation of the variance of each trait.

Genetic correlations $\left(r_{g}\right)$ between traits were calculated using equation [4]:

$$
\mathrm{r}_{\mathrm{g}}=\frac{\operatorname{Cov}\left(a_{h: k 0}, a_{h^{\prime}: k 0}\right)}{\sqrt{V\left(a_{h: k 0}\right) * V\left(a_{h^{\prime}: k 0}\right)}}
$$

where $\operatorname{Cov}\left(a_{h: k 0}, a_{h^{\prime}: k 0}\right)$ is the covariance between the first genetic regression coefficients for two traits $h$ and $h^{\prime}$, and $V\left(a_{h: k 0}\right)$ and $V\left(a_{h^{\prime}: k 0}\right)$ are the respective variances for the two traits.

\section{RESULTS}

The mean MUN concentration for the final dataset of 36,074 test-day records was $12.61 \mathrm{mg} / \mathrm{dl}$ with a range from 1 to $50 \mathrm{mg} / \mathrm{dl}$. The distributions of MUN in each lactation were not significantly different from normal.
Means and standard deviations for all four traits, in each lactation, are in Table 1. Means for yield traits were within the ranges typically observed in Canada. The mean MUN concentration for primiparous cows of $\mathrm{mg} / \mathrm{dl} 12.41$ was lower than the means for either second $(12.80 \mathrm{ml} / \mathrm{dl})$ or third $(12.74 \mathrm{ml} / \mathrm{dl})$ lactations. The Center for Animal Health and Productivity (2002) reported similar trends in MUN across lactations based on more than 4 million records from Pennsylvania. They observed means of $12.88,13.20$, and $13.05 \mathrm{mg} / \mathrm{dl}$ for lactations 1,2 , and $\geq 3$, respectively. An analysis of data from the Dairy Records Processing Center in Raleigh, North Carolina (Vallimont et al., 2002), also indicated increased MUN in second lactation.

The overall mean for MUN was similar to the value obtained by Hof et al. (1997), who reported a mean for MUN of $12.6 \mathrm{mg} / \mathrm{dl}$ (range of 9.0 to $18.3 \mathrm{mg} / \mathrm{dl}$ ) based on a small group of 125 cows. However, greater values were reported by other researchers. Broderick and Clayton (1997) reported a mean MUN of $14.8 \mathrm{mg} / \mathrm{dl}$, with a range of 3 to $28 \mathrm{mg} / \mathrm{dl}$, and Jonker et al. (1998) reported a mean of $13.51 \mathrm{mg} / \mathrm{dl}$. All of these studies were based on feeding experiments and involved relatively few $(<500)$ animals. In contrast, means have been calculated on much larger sets of data. A recent study in Pennsylvania used records from the period between September 1995 to September 2002 (Center for Animal Health and Productivity, 2002) and the overall mean of $13.03 \mathrm{mg} / \mathrm{dl}$ was closer to the values observed in Canada than were the results of Broderick and Clayton (1997) or Jonker et al. (1998).

\section{Environmental Effects}

Table 2 has the $P$ values of associated with the ANOVA of environmental effects on test-day observations of MUN in lactations one to three. The various environmental effects (and the cow effect) explained the majority of the variance in MUN, as the $\mathrm{R}^{2}$ of the model was between 0.84 and 0.86 for all three lactations. In all lactations, effects of HTD were highly statistically significant $(P<0.0001)$. The combined effects of age and season of calving and DIM was also important, particularly in first lactation. Figure 1 shows the trends in 
Table 2. Results ( $P$-values) for tests of significance of various environmental factors and yield traits on test-day concentrations of milk urea nitrogen in lactations 1 to 3 .

\begin{tabular}{lccc}
\hline Factor & First & Second & Third \\
\hline Herd-test-day $^{1}$ & $<0.0001$ & $<0.0001$ & $<0.0001$ \\
Age and time $^{1}$ & $<0.0001$ & 0.024 & 0.084 \\
Milk & $<0.0001$ & 0.18 & 0.16 \\
Fat & 0.030 & 0.84 & 0.069 \\
Protein & 0.002 & $<0.0001$ & 0.11 \\
\hline
\end{tabular}

${ }^{1}$ Combinations of 3 age at calving, 2 season of calving, and 31 stage of lactation classes for each lactation.

MUN across each lactation (based on Least Square Means averaged across the 3 age groups per lactation). As had been indicated by the overall raw means by lactation, MUN tended to be lower in first lactation than in second or third. No clear association was observed between MUN and age at calving within lactation (results not shown).

In all lactations, the lactation curves for MUN were generally a mirror image (reflected across the $\mathrm{X}$-axis) of typical curves for yield (Figure 1), being slightly elevated at the start of lactation, reaching to a nadir in early lactation (d 30 to 40), and then rising steadily to maximum values at the end of the lactation. Ng-KwaiHang et al. (1985) and DePeters and Cant (1992) reported similar trends in MUN with stage of lactation in first parity. Broderick and Clayton (1997) also found a positive relationship between MUN and DIM, but the data analyzed by Spicer et al. (2000) indicated that MUN increased during the first $3 \mathrm{wk}$ of lactation, then remained steady for the remainder of the lactation. The increase in MUN after the peak of lactation may be due to physiological changes and the decreasing metabolic demands of lactation. In many herds, cattle are managed in groups, according to stage of lactation and pro-

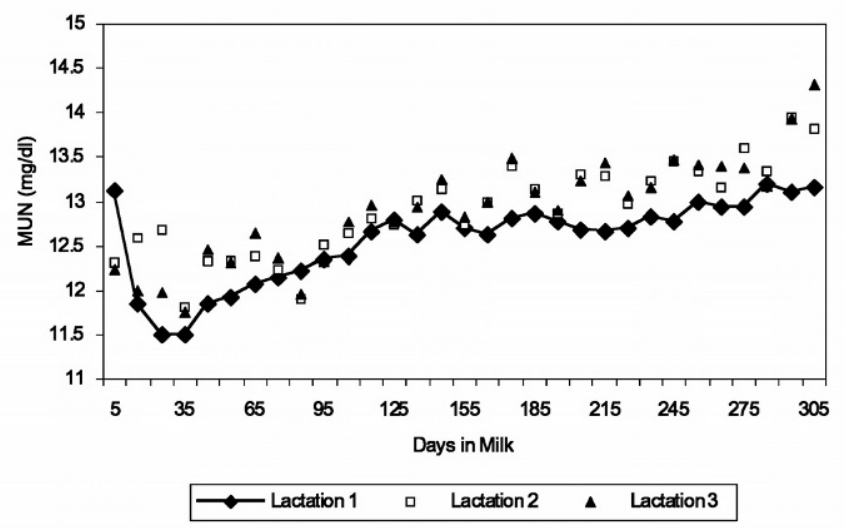

Figure 1. Trends (daily least square means) in concentrations of milk urea nitrogen across lactations for parities one to three. duction level, and fed different diets accordingly. Cattle in the latter half of lactation are often grouped together, but fed a diet balanced for the higher producing cattle in the group. As production decreases throughout lactation, less protein needed from the diet and the lower producing (later lactation) cattle in such groups may be increasingly higher levels of excess protein and releasing greater proportions of urea in blood and milk. The high statistical significance of the HTD effect on MUN indicated that management is an important source of variability in MUN. Management factors such as more or less precisely decreasing the concentration of protein in the diet as production decreases may play a crucial role in maintaining optimum or stable MUN levels throughout lactation.

No consistently strong relationship was observed between MUN and the various yield traits. Absolute values of raw phenotypic correlations between MUN and the yield traits in the different lactations were all $<0.10$ (results not shown). According to the ANOVA (Table $2)$, relationships with MUN were significant $(P<0.05)$ for all three yield traits in first lactation, but regression coefficients were small. In later lactations, only protein yield in second lactation was significantly associated with MUN.

\section{Genetic Parameters}

Heritabilities. Estimates (posterior means) of heritabilities of for the three yield traits and MUN in the three lactations are in Table 3. Heritabilities of yield traits ranged from 0.35 (milk, lactation three) to 0.59 (fat, lactation two). These results are within the range of daily heritabilities previously reported for the Canadian Holstein population when a test-day model and random regressions were employed for estimation of genetic parameters (Jamrozik and Schaeffer, 1997). The heritabilities obtained for average daily levels of MUN were $0.44,0.59$, and 0.48 for lactations one, two, and three, respectively. Corresponding genetic standard deviations of MUN were 1.36, 1.30, and $1.12 \mathrm{mg} /$ $\mathrm{dl}$ for the three lactations. Residual variances (no table shown) tended to be highest in early lactation and decreased as the lactation progressed, meaning that heritabilities increased with increasing DIM. All posterior means of heritabilities were at least five times greater than the respective posterior standard deviations and the posterior distributions did not include zero. These heritabilities are moderate to high and generally of the same magnitude as those obtained for the production traits. These results indicate that selection could be an effective approach for altering MUN.

Another recent study (Vallimont et al., 2002) estimated daily heritabilities for MUN, using data from 
Table 3. Estimates ${ }^{1}$ of heritabilties of yield traits and concentration of milk urea nitrogen (MUN) in lactations one to three (posterior SD in parentheses).

\begin{tabular}{lllll}
\hline Lactation & Milk & Fat & Protein & MUN \\
\hline 1 & $0.48(0.09)$ & $0.38(0.08)$ & $0.42(0.07)$ & $0.44(0.02)$ \\
2 & $0.45(0.10)$ & $0.59(0.09)$ & $0.47(0.09)$ & $0.59(0.07)$ \\
3 & $0.35(0.08)$ & $0.50(0.09)$ & $0.36(0.07)$ & $0.48(0.07)$ \\
\hline
\end{tabular}

${ }^{1}$ Posterior means.

the Dairy Records Processing Center in Raleigh, North Carolina. A random regression model was also employed in that study, but the model differed from the present approach in that no fixed lactation curve was considered, and additive genetic and permanent environmental effects were fitted using three-parameter quadratic polynomials. In that study, MUN data had been obtained based on either IR or wet chemistry (WC) procedures, and the two types of data were considered separately. First and second lactations were analyzed separately as well. The estimates of heritability from the Raleigh data were much lower than those obtained in this study, particularly for the WC data. In first lactation, heritabilities of MUN ranged from about 0.20 to 0.30 for IR data, but only between 0.12 and 0.20 for WC. In contrast to this study, heritabilities were slightly lower in second lactation than in first lactation, ranging from 0.17 to 0.24 for IR and 0.09 to 0.12 for WC.

Genetic correlations. The genetic correlations between MUN and milk production traits for the first three parities are summarized in Table 4 . For lactation one, the genetic correlations between MUN and milk (0.11), fat (0.01), and protein (0.04) yields were positive but close to zero. None of the posterior means for these correlations were greater than its posterior standard deviation, indicating essentially no genetic association between MUN and yield in first lactation. The genetic correlations in lactation two were higher than those for lactation one (ranging from 0.17 to 0.32 ), but posterior standard deviations were also greater, because fewer data were considered. Genetic correlation between the yield traits and MUN were inconsistent, being near zero for milk and protein and moderately positive for fat. These weak genetic relationships between yield and MUN suggest that selection to alter MUN concentra-

Table 4. Estimates ${ }^{1}$ of genetic correlations between yield traits and concentration of milk urea nitrogen in lactations one to three (posterior SD in parentheses).

\begin{tabular}{lrll}
\hline Lactation & \multicolumn{1}{l}{ Milk } & Fat & Protein \\
\hline 1 & $0.11(0.04)$ & $0.01(0.05)$ & $0.04(0.04)$ \\
2 & $0.17(0.14)$ & $0.32(0.10)$ & $0.22(0.12)$ \\
3 & $-0.05(0.16)$ & $0.20(0.13)$ & $0.06(0.15)$ \\
\hline
\end{tabular}

${ }^{1}$ Posterior means. tions would have little effect on yield, except to marginally decrease selection intensity.

\section{DISCUSSION AND CONCLUSIONS}

For inclusion in a breeding program, a given trait must be measurable, variable, heritable, and economically important. The trait MUN has several of these qualities. First, MUN can be easily measured objectively and inexpensively. The testing of milk for MUN is an option offered to many producers enrolled in DHIA programs in North America. Although MUN testing was initially offered to provide farmers with a tool for management of nutrition rather than for genetic selection, the MUN data routinely collected could easily be adapted and used for genetic evaluation. The recording of SCC data was also originally offered by DHIA as a service for management and culling decisions, but genetic evaluations were later developed using the routinely collected data (e.g., Schutz, 1994). A genetic evaluation for MUN could follow the same model. Phenotypic scores for MUN are also continuously and normally distributed, meaning that standard linear models can be applied for statistical analysis and neither data transformations nor nonlinear analyses would be required for genetic evaluation. Sufficient variability exists in the population, meaning that differences among animals can be easily identified. The standard deviation of daily MUN in the data used for this study was approximately $3.50 \mathrm{mg} / \mathrm{dl}$, with a range of $50 \mathrm{mg} / \mathrm{dl}$. According to the results of this study (Table 3 ) the heritability of MUN is within the range of 0.40 , similar to estimates of heritabilities for milk, fat, and protein yield from the same data. Clearly, this level of genetic influence is sufficient for genetic response. In addition, no strong antagonistic genetic correlations seem to exist between MUN and the yield traits (Table 4).

Questions remain, however, about the economic importance of MUN, from a genetic perspective. The direct economic value of MUN is unclear. Unlike SCC, milk producers do not receive price bonuses or penalties with respect to MUN. High levels of MUN are generally interpreted as an indication of inefficient utilization of protein, which is economically unfavorable. In theory, because the correlation between MUN and yield is low, 
selection for increased MUN could favor cattle that produce more milk with respect to the quantity of protein consumed. However, the rules about MUN and protein utilization are applicable on a herd level for management purposes, and extension to the genetics of protein utilization on the cow level may not be appropriate.

Even if MUN has little or no direct economic value, it may be useful in a selection program if it is genetically associated with another trait or traits of economic importance that are difficult to record. High values of MUN indicate an imbalance of protein and energy. Although this disequilibrium is often assumed to be associated with an excess of protein in the diet, logic suggests that it may also result from a relative deficiency of energy. Previous studies have demonstrated a link between negative energy balance and metabolic problems (Collard et al., 2000). Presence of metabolic disorders is an economically important trait that is difficult to measure and record on either a consistent and objective basis or on a continuous quantitative scale. For these reasons, and because metabolic disorders can be caused by a number of nongenetic factors, estimates of heritabilities of metabolic diseases have been low (e.g., Lyons et al. 1991, Uribe et al. 1995, Van Dorp et al. 1998), and direct selection to decrease their incidence has not been widely implemented. In reality, no clear link between MUN and metabolic diseases has yet been established, but this absence is at least partially due to a lack of studies designed to examine the presence of such a relationship.

If a genetic relationship exists between MUN and metabolic disorders, EBV for MUN could be used for indirect selection to decrease metabolic disorders. A similar approach is currently being applied by using EBV for SCC (SCS) to select indirectly for mastitis resistance. Because SCC and mastitis are genetically correlated but SCC is more highly heritable, indirect selection based on SCC is expected to be more efficient than direct selection (Strandberg and Shook, 1989) The trait MUN seems to be even more highly heritable than is SCC, so indirect selection using this trait seems possible.

A relationship between MUN and fertility has also been noted on the phenotypic scale (Butler et al., 1996, Rajala-Schultz et al., 2001). Butler et al. (1996) divided cattle into groups based on MUN and found that rate of pregnancy was reduced by $20 \%$ among the high group of cattle with MUN $>19 \mathrm{mg} / \mathrm{dl}$. Rajala-Schultz et al. (2001) used survival analysis to study the relationship between MUN and days to calving and conception. Cattle were assigned to various classes, based on their MUN scores in the month previous to conception. Compared to herdmates with MUN $>15.4 \mathrm{mg} / \mathrm{dl}$, cows with MUN levels below 10.0 were 2.4 times more likely to be confirmed pregnant in a subsequent exam. The advantage decreases as MUN increased, as cows with MUN levels between 10.0 and $12.7 \mathrm{mg} / \mathrm{dl}$ were only 1.4 times more likely to be confirmed pregnant than were cows with MUN $>15.4 \mathrm{mg} / \mathrm{dl}$. Assuming genetic factors play a role in this relationship between MUN and fertility, perhaps MUN can be used to improve the precision and accuracy of EBV for fertility, in addition to possibly providing a selection tool for metabolic disorders.

In conclusion, according to the results of this study, the heritability of MUN is similar to that of yield traits and no strong antagonistic correlations exist between MUN and various measures of yield. These factors make MUN a candidate for selection, except that the direct economic value of MUN is unclear. The most promising use of MUN could be as a tool for indirect selection for fitness. However, estimates of genetic relationships between MUN and health and fertility traits are currently not available. Future research on MUN should examine the genetic and phenotypic correlations between MUN and various fitness traits. Particular attention should be paid to relationships between MUN and traits related to fertility.

\section{ACKNOWLEDGMENTS}

The authors would like to thank the Ontario Ministry of Agriculture and Food and the Dairy Farmers of Ontario for supporting this project financially. Thanks go out also to the Ontario Dairy Herd Improvement Corporation and the Canadian Dairy Network for the contributions of the data used in this study.

\section{REFERENCES}

Broderick, G. A., and M. K. Clayton. 1997. A statistical evaluation of animal and nutritional factors influencing concentrations of milk urea nitrogen. J. Dairy Sci. 80:2964-2971.

Butler, W. R., J. J. Calalman, and S. W. Beam. 1996. Plasma and milk urea nitrogen in relation to pregnancy rate in lactating dairy cattle. J. Anim. Sci. 74:858-865.

Center for Animal Health and Productivity. 2002. Pennsylvania MUN Values. http://cahpwww.vet.upenn.edu/mun/ pa_mun_summ.html. Accessed Nov. 31, 2002.

Collard, B. L., P. J. Boettcher, J. C. M. Dekkers, D. Petitclerc, and L. R. Schaeffer. 2000. Relationships between energy balance and health traits of dairy cattle in early lactation. J. Dairy Sci. 83:2683-2690.

DePeters, E. J., and J. P. Cant. 1992. Nutritional factors influencing the nitrogen composition of bovine milk: a review. J. Dairy Sci. 75:1043-2070.

Eicher, R., E. Bouchard, and M. Bigras-Poulin. 1999. Factors affecting milk urea nitrogen and protein concentrations in Quebec dairy cows. Prev. Vet. Med. 39:53-63.

Emanuelson, U., and L. Andersson. 1986. Genetic variation in milk acetone in Swedish dairy cows. J. Vet. Med. 33:600-608.

Ferguson, J. D., 2002. Milk Urea Nitrogen. http://cahpwww.vet.upenn.edu/mun/mun_info.html. Accessed November 12, 2002.

Hof, G., M. D. Vervoorn, P. J. Lenaers, and S. Tamminga. 1997. Milk urea nitrogen as a tool to monitor the protein nutrition of dairy cows. J. Dairy Sci. 80:3333-3340. 
Jamrozik, J., and L. R. Schaeffer. 1997. Estimate of genetic parameters for a test day model with random regressions for yield traits of first lactation Holsteins. J. Dairy Sci. 80:762-770.

Jamrozik, J., L. R. Schaeffer, and K. A. Weigel. 2002. Estimates of genetic parameters for single- and multiple-country test-day models. J. Dairy Sci. 85:3131-3141.

Jonker, J. S., R. A. Kohn, and R. A. Erdman. 1998. Using milk urea nitrogen to predict nitrogen excretion and utilization efficiency in lactating dairy cows. J. Dairy Sci. 81:2681-2692.

Lyons, D. T., A. E. Freeman, and A. L. Kuck. 1991. Genetics of health traits in Holstein cattle. J. Dairy Sci. 74:1092-1100.

Ng-Kwai-Hang, K. F., J. F. Hayes, J. E. Moxley, and H. G. Monardes. 1985. Percentages of protein and nonprotein nitrogen with varying fat and somatic cells in bovine milk. J. Dairy Sci. 68:12571262.

Rajala-Schultz, P. J., W. J. A. Saville, G. S. Frazer, and T. E. Wittum. 2001. Association between milk urea nitrogen and fertility in Ohio dairy cows. J. Dairy Sci. 84:482-489.

SAS Institute Inc. 1990. SAS/STAT User's Guide. Version 6, 4th ed., Cary, NC.
Schaeffer, L., J. Jamrozik, G. J. Kistemaker, and B. J. Van Doormaal. 2000. Experience with a test-day model. J. Dairy Sci. 83:11351144.

Schutz, M. M. 1994. Genetic evaluation of somatic cell scores for United States dairy cattle. J. Dairy Sci. 77:2113-2129.

Spicer, L. J., C. C. Francisco, D. Jones, and D. N. Waldner, 2000. Changes in milk urea nitrogen during early lactation in Holstein cows. 2000 Animal Science Research Report. 2000:169-171.

Strandberg, E., and G. E. Shook. 1989. Genetic and economic responses to breeding programs that consider mastitis. J. Dairy Sci. 72:2136-2142.

Uribe, H. A., B. W. Kennedy, S. W. Martin, and D. F. Kelton. 1995 Genetic parameters for common health disorders of Holstein cows. J. Dairy Sci. 78:421-430.

Vallimont, J. E., J. Hyman, G. W. Rogers, L. A. Holden, M. L. O'Connor, C. D. Dechow, and J. B. Cooper. 2002. A population study of milk urea nitrogen. J. Dairy Sci. 85(Suppl. 1):323. (Abstr.)

Van Dorp, T. E., J. C. Dekkers, S. W. Martin, and J. P. Noordhuizen 1998. Genetic parameters of health disorders, and relationships with 305-day milk yield and conformation traits of registered Holstein cows. J. Dairy Sci. 81:2264-2270. 